\title{
An early political election problem
}

\author{
D. Lesmono* $\quad$ E. J. Tonkes ${ }^{\dagger} \quad$ K. Burrage ${ }^{\ddagger}$
}

(Received 8 August 2003; revised 8 December 2003)

\begin{abstract}
Under the democratic systems of government instilled in many sovereign states, the party in government maintains a constitutional right to call an early election. Whereas the constitution states that there is a maximum period between elections, early elections are frequently called. This right to call an early election gives the government a control to maximize its remaining period in power. We find the optimal control for the government by locating an exercise boundary, which indicates whether or not a premature election should be called. This problem draws upon the methods of optimal stopping and stochastic control.
\end{abstract}

${ }^{*}$ Dept. of Maths, University of Queensland, Brisbane, Australia. mailto:dlesmono@maths.uq.edu.au \& Dept. of Maths, Parahyangan Catholic University, Bandung, InDONESIA. mailto: jdharma@home.unpar.ac.id

${ }^{\dagger}$ Dept. of Maths, University of Queensland, Brisbane, Australia. mailto: ejt@maths.uq. edu.au

${ }^{\ddagger}$ Dept. of Maths, University of Queensland, Brisbane, Australia. mailto:kb@maths.uq.edu.au

See http://anziamj.austms.org.au/V45/CTAC2003/Lesm/home.html for this article, (c) Austral. Mathematical Soc. 2003. Published December 14, 2003. ISSN 1446-8735 


\section{Contents}

1 Introduction

C17

2 Finite state and discrete time model

2.1 Formulation and solution method . . . . . . . . . . C21

2.2 Parameter fitting . . . . . . . . . . . C C26

2.2.1 Transition probabilities and parameter estimation . C26

2.2.2 Winning probabilities, sampling and response errors

$\mathrm{C} 27$

3 Results

C29

3.1 Expected remaining life and exercise boundary . . . . . . .

3.2 No early election permitted . . . . . . . . . . . .

4 Conclusions and further research

C31

References

C32

\section{Introduction}

Under the democratic systems of government in many sovereign states, the party in government maintains a constitutional right to call an early election. Whereas the constitution states that there is a maximum period between elections (typically 3 or 4 years), early elections are frequently called. For example, the Australian Constitution and Commonwealth Electoral Act gives the Federal Government the right to call an early election, subject to approval by the monarch's representative.

This right to call an early election gives the government a control with which to optimize its objective of remaining in power for as long as possible. In some sense, the party in government has an option, which it can freely exercise. We want to devise the optimal control for the government by locating 
an exercise boundary, which indicates whether or not a premature election should be called. This problem draws upon the body of literature on optimal stopping problems and stochastic control. The problem can be compared with the determination of early exercise for American options in finance.

Balke [2] investigated and modelled the election timing as an optimal stopping problem by considering the benefits and costs of the government by calling an early election. Kayser [7] treated election timing as a finite horizon optimal stopping problem and developed a model to predict the degree of surfing (opportunistic timing) and manipulation (politically motivated economic intervention) by considering institutional structure and voter characteristics. Election timing as an endogenous policy variable in relation with other factors such as growth rate, electoral support and other subsequent economic performance has also been investigated, mathematically modelled and applied in several countries such as India [4], Japan [5] and United Kingdom [12, 13].

In case an election is called at some time $t$, a mechanism is needed to gauge the likelihood of the government being returned to power. We have chosen to use popular opinion polls (Morgan polls: http://www.roymorgan.com.au) to measure the voting intentions of the Australian public for the Australian Federal House of Representatives. The format of the poll has varied over time, but consistently asks the voting intentions from a sample of the voting public. In more recent polls, the two-party preferred voting intentions are recorded. In general, samples have been taken every two weeks, but once an election date is announced, polls are taken approximately weekly, and even more frequently in the days leading up to the election. However, all of the data contains irregular sampling intervals, owing to public holidays, etc.

Our model assumes that opinion polls are driven by random processes. The announcement, distribution and dissemination of news, (whether policy announcements or exogenous news items) drive the voting intentions of the public. Figure 1(a) shows the two-party-preferred voting intentions of the Australian public between Australia's major opposing parties, the LNP 



Figure 1: (a) Two-party preferred with significant events 1993-2002; (b) Simulated process 
(Liberal and National Party) and ALP (Australian Labor Party) over the last decade or so, along with significant events, which were taken from [11] and [14].

Balke [2] and other authors [7, 12] have considered the early election problem previously with somewhat arbitrary expressions for the poll process $S_{t}$ and conditional probabilities of reelection. Our contribution has been to calculate early exercise boundaries with a realistic model and with parameters fitted to observed data. Also, our techniques are applicable for data sets from other countries or state. We have also used a multinomial tree approach which permits the process $S_{t}$ to diffuse with large jumps, reminiscent of the observed behaviour. The visualisations of the results in surface plots are also quite insightful.

\section{Finite state and discrete time model}

Suppose there are two major parties, $A$ and $B$, which dominate the election process. We consider votes to other parties will be distributed to these parties through the preferential voting system, or that there is a competition for the seats which are not won by the minor parties. At any time, suppose that proportion $P_{A}$ of polled persons intends to vote for party $A$ and $P_{B}$ intends to vote for party $B$. Then our main variable under study is $S=P_{A}-P_{B}$. We maintain the condition that $-1<S<1$ as popularity cannot exceed $100 \%$.

In the Australian federal electoral system, voters list their preferences for candidates and then preferences are allocated from unpopular to the more popular candidates until a winner is determined. Consequently, although many voters claim, and indeed do, register their primary vote for a minor party, the deciding quantity is the order in which the two major parties are listed. So, two-party-preferred poll data is most suitable for our study.

We assume that the longest allowable period between elections is $Y$ years 
and a constant lead time $T_{L}=k \delta t$, for some integer $k$, takes place between announcing the election and holding the election. This period is somewhat in the hands of the government, but according to the Australian constitution, it must lie between 33 and 68 days and is further restricted as elections must be held on a Saturday. This constant lead time simplifies the solution method, and we note that recent elections have all had lead times around the minimum. We also assume that all requests for an election will be approved.

We model $S$ as a random process which is mean reverting, and has no memory of its own history (Markovian). Let there be $m$ arbitrary states of popularity $S_{i} \in(-1,1)$ and $n$ equal time intervals dividing the $Y$ years. Using historical data, we determine the probability of winning the election, given that on election day the government is in state $S_{j}$ in the polls. This quantity contains the exaggerated majority effect, sampling and response errors and any other inaccuracies inherent in any polling system.

Later in our computation, we used the number of states, $m=50$ for $S_{i}$, $i=1,2, \ldots, m$, lead time $T_{L}=0.12$ year and time step $\delta t=0.04$ year. The number of time steps $n=Y / \delta t+1$ with $Y$ either three or four (year term). We fit an approximate normal distribution to the historical states and use this to define the grid $S_{i}$.

\subsection{Formulation and solution method}

The notations used in the formulation of our problems are as follows

- $P_{i k}(t)$ : transition probability from poll state $S_{i}$ to state $S_{k}$ over period $t$. It measures the diffusion in polls over period $t$. We assume stationarity of the process, so the transition probabilities remain unchanged even during the election campaigns.

- $Q_{k j}$ : conditional probability that the true state of voting intentions 
is $S_{k}$ given that poll state is $S_{j}$. It is the correction term, which contains sampling and response errors.

- $\operatorname{Pr}\left(W \mid S_{j}\right)$ : conditional probability of winning the election from true state $S_{j}$. It contains the exaggerated majority effect.

- $\mathbb{E}\left(L \mid S_{i}, t\right)$ : conditional expected remaining life of the government given poll state $S_{i}$ and time $t \in[0, Y]$ into current term.

We define the poll state of voting intentions as the state of the process indicated by poll results (contains sampling and response errors) and the true state as the real state of the process (when the election is held, the true state is the election result). In each state at every time step the government can call an early election. The single control afforded to the government in this problem is the action of stopping (calling an election), and our problem centres around this optimal stopping problem. We implement numerical dynamic programming to solve the recursive formulation for the expected time remaining in government.

If calling an early election, time $T_{L}$ will elapse with certainty after the announcement. In case the government wins the election, the life of the government is extended and we again consider the same problem, but with $t$ reset to zero. If choosing not to call an early election, the government remains in power up to the next time step $\delta t$ with certainty. At the new time $t+\delta t$ the poll state will diffuse to a new value and again the decision whether or not to call an early election is re-evaluated. At the final time $t=$ $Y$, an election must be held, so the latest time to call for an election is at $t=Y-T_{L}$. The expected remaining life when calling an early election and calling no election are, respectively:

$$
\begin{aligned}
& \mathbb{E}\left(L \mid S_{i}, t\right)=T_{L}+\sum_{j=1}^{m} \mathbb{E}\left(L \mid S_{j}, 0\right) P_{i k}\left(T_{L}\right) Q_{k j} \operatorname{Pr}\left(W \mid S_{j}\right), \\
& \mathbb{E}\left(L \mid S_{i}, t\right)=\delta t+\sum_{j=1}^{m} \mathbb{E}\left(L \mid S_{j}, t+\delta t\right) P_{i j}(\delta t),
\end{aligned}
$$


where we use the Einstein convention for summation over the repeated index $k$. So, the expected remaining life is the maximum between calling an early election and calling no election, that is,

$$
\begin{gathered}
\mathbb{E}\left(L \mid S_{i}, t\right)=\max \left\{T_{L}+\sum_{j=1}^{m} \mathbb{E}\left(L \mid S_{j}, 0\right) P_{i k}\left(T_{L}\right) Q_{k j} \operatorname{Pr}\left(W \mid S_{j}\right),\right. \\
\left.\delta t+\sum_{j=1}^{m} \mathbb{E}\left(L \mid S_{j}, t+\delta t\right) P_{i j}(\delta t)\right\} .
\end{gathered}
$$

We describe the iterative scheme implemented to determine the expected life $\mathbb{E}\left(L \mid S_{i}, t\right)$, which for each $t$ is a vector in $\mathbb{R}_{+}^{m}$. Because the solution exists, we can solve the problem any way, comfortable in the knowledge that if the method works, then it will arrive at the right solution. We base our method on Picard iterates [10]. The general idea is starting at time $t=0$ using an initial estimate for the expected remaining life at time zero, we calculate the expected life at the final time $(t=Y)$ and then move backward until we find the new expected remaining life at time zero which will not match up with our first estimate. We replace our initial estimate with the current vector and repeat this procedure. Formally, we define an operator $T$ which takes any $E \in \mathbb{R}_{+}^{m}$ and returns $T(E) \in \mathbb{R}_{+}^{m}$. In our paper, the $i$ th component of $E$ at time $t, E_{i}(t)$, will represent an estimate for $\mathbb{E}\left(L \mid S_{i}, t\right)$ and $[T(E)]_{i}(t)$ will be an improved estimate for $\mathbb{E}\left(L \mid S_{i}, t\right)$.

Given $E^{0}=\left(E_{1}^{0}, \ldots, E_{m}^{0}\right) \in \mathbb{R}_{+}^{m}$, calculate for $1 \leq i \leq m$,

$$
E_{i}^{1}(Y)=\sum_{j=1}^{m} E_{j}^{0}(0) Q_{i j} \operatorname{Pr}\left(W \mid S_{j}\right) .
$$

Then $E_{i}^{1}\left(Y-T_{L}\right)=T_{L}+\sum_{j=1}^{m} E_{j}^{0}(0) P_{i k}\left(T_{L}\right) Q_{k j} \operatorname{Pr}\left(W \mid S_{j}\right)$ and

$$
E_{i}^{1}\left(Y-T_{L}-\delta t\right)=\max \left\{T_{L}+\sum_{j=1}^{m} E_{j}^{0}(0) P_{i k}\left(T_{L}\right) Q_{k j} \operatorname{Pr}\left(W \mid S_{j}\right),\right.
$$




$$
\begin{gathered}
\left.\delta t+\sum_{j=1}^{m} E_{j}^{1}\left(Y-T_{L}\right) P_{i j}(\delta t)\right\}, \\
E_{i}^{1}\left(Y-T_{L}-v \delta t\right)=\max \left\{T_{L}+\sum_{j=1}^{m} E_{j}^{0}(0) P_{i k}\left(T_{L}\right) Q_{k j} \operatorname{Pr}\left(W \mid S_{j}\right),\right. \\
\left.\delta t+\sum_{j=1}^{m} E_{j}^{1}\left(Y-T_{L}-(v-1) \delta t\right) P_{i j}(\delta t)\right\} .
\end{gathered}
$$

Continue the calculation until

$$
\begin{aligned}
& E_{i}^{1}(\delta t)= \max \left\{T_{L}+\sum_{j=1}^{m} E_{j}^{0}(0) P_{i k}\left(T_{L}\right) Q_{k j} \operatorname{Pr}\left(W \mid S_{j}\right),\right. \\
&\left.\delta t+\sum_{j=1}^{m} E_{j}^{1}(2 \delta t) P_{i j}(\delta t)\right\}, \\
& E_{i}^{1}(0)=\max \left\{T_{L}+\sum_{j=1}^{m} E_{j}^{0}(0) P_{i k}\left(T_{L}\right) Q_{k j} \operatorname{Pr}\left(W \mid S_{j}\right),\right. \\
&\left.\delta t+\sum_{j=1}^{m} E_{j}^{1}(\delta t) P_{i j}(\delta t)\right\} .
\end{aligned}
$$

We then define $T\left(E^{0}\right)=E^{1}(0) \in \mathbb{R}_{+}^{m}$. This is our first iteration. For the next iteration, we calculate $E^{2}=T\left(E^{1}\right)$. The aim of the method is to obtain $E_{i}^{k}(t) \rightarrow \mathbb{E}\left(L \mid S_{i}, t\right)$ as $k \rightarrow \infty$. Our computational approach is abbreviated to the simple iterative Algorithm 1. We define 'error' as the max $L^{2}$ norm

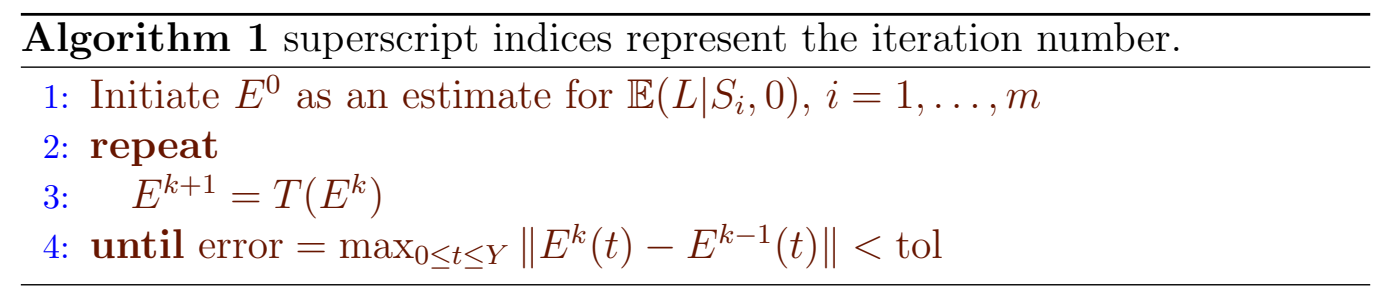


of the difference between the expected life in two consecutive loops over all times. Convergence is obtained when this difference is less than a tolerance value, 'tol', whereupon we approximate $\mathbb{E}\left(L \mid S_{i}, t\right)$ with $E_{i}^{k}(t)$.

Lemma 1 There exists a solution to the system of nonlinear equations for the expectation $\mathbb{E}\left(L \mid S_{i}, t\right)$ in (3).

Proof: The proof follows by the Brouwer Fixed Point Theorem [8, p.200]. Given a vector $E^{0}$ that represents an initial estimate for $\mathbb{E}\left(L \mid S_{i}, 0\right)$, define the operator $T$ as above. Let $P^{*}=\max _{S_{i}} \operatorname{Pr}\left(W \mid S_{i}\right)$ and note $P^{*}<1$ if $S_{i} \neq 1$ for any $i$. Let $R=\frac{Y}{1-P^{*}}+1$ and define

$$
\Omega=\left\{x \in \mathbb{R}^{m}:\|x\|_{\infty} \leq R\right\} .
$$

We claim that $T(\Omega) \subset \Omega$. Let $E^{0} \in \Omega$. By monotonicity, we have $T\left(E^{0}\right) \leq$ $T\left(E^{*}\right)$, where

$$
E^{*}=\left(\max \left(E^{0}\right), \max \left(E^{0}\right), \ldots, \max \left(E^{0}\right)\right) \in \Omega .
$$

Consider a system where $\operatorname{Pr}\left(W \mid S_{i}\right)=P^{*}$ for all $S_{i}$. Then in such a system, $\widetilde{T}\left(E^{*}\right) \geq T\left(E^{*}\right)$, where $\widetilde{T}$ has the new probabilities of winning $P^{*}$. In this new system, there is no incentive to call an election early, so we only need to consider the second term in equation (3), except at $t=Y$ years. So, $\widetilde{E}\left(L \mid S_{i}, \delta t\right)=(Y-\delta t)+P^{*} \widetilde{E}\left(L \mid S_{i}, 0\right)$ and for each component

$$
\widetilde{T}\left(E^{0}\right)=\widetilde{\mathbb{E}}\left(L \mid S_{i}, 0\right)=\delta t+(Y-\delta t)+P^{*} \widetilde{\mathbb{E}}\left(L \mid S_{i}, 0\right) .
$$

Rearranging, $\widetilde{T}\left(E^{0}\right)=\widetilde{\mathbb{E}}\left(L \mid S_{i}, 0\right)=\frac{Y}{1-P^{*}}$. But we have $R=\frac{Y}{1-P^{*}}+1$ which yields a contradiction. So, $T$ is a continuous, mapping from a convex set $\Omega$ into itself and by the Brouwer Fixed Point Theorem, there must be a fixed point. 


\subsection{Parameter fitting}

\subsubsection{Transition probabilities and parameter estimation}

We use a maximum likelihood method to estimate the parameters of the transition probabilities with an assumption that the underlying process consists of increments driven by the current state and a Gaussian process. Under an assumption of continuous states, $-1<S<1$, if the poll is in state $S_{t}$ at time $t$, it will move to a state $S_{t+\delta t}$ a time $\delta t$ later, where the state $S_{t+\delta t}$, falls in a continuum and is normally distributed with mean $S_{t}+\mu\left(S_{t}, t+\delta t\right)$ and variance $\sigma^{2}\left(S_{t}, t+\delta t\right)$. We estimate $\mu$ and $\sigma$ with a maximum likelihood estimator (MLE). This method is capable of handling uneven time increments which we encounter in the data. We presuppose our model to be the Stochastic Differential Equation (SDE)

$$
d S_{t}=-\mu\left(\frac{S_{t}}{1-S_{t}^{2}}\right) d t+\sigma d W_{t}
$$

where $W_{t}$ is a Wiener process and $\mu$ and $\sigma$ are constants. Our formulation for the drift coefficient stems from several arguments. By Lemma 6.3 of [6] if $S_{0} \in$ $(-1,1)$ and $\mu>\frac{1}{2} \sigma^{2}$, then the process $S_{t}$ governed by equation (5) remains within $(-1,1)$ for all time. The negative autocorrelation discovered in a basic time series analysis of the data supports a mean reverting coefficient, and this holds in our model for $\mu>0$. The strength of mean reversion logically becomes stronger as the magnitude of $S$ becomes larger as the losing party will take measures to overcome their deficiencies in the polls.

We make an assumption that the poll process exhibits constant volatility $\sigma$. This underlying assumption is analogous to the founding studies in financial mathematics where stock prices are assumed to obey constant volatility in the 'Black-Scholes' world [3]. In actual fact, the poll data possesses a weak time dependence, showing clustering in a similar way to the stochastic volatility models of stock price data. However, in this study our optimal control analysis is completed neglecting any term structure in volatility. 
With this formulation, we now apply maximum likelihood estimation. First, we take the Euler discretization to our presupposed model above: for $i=1,2, \ldots, N-1$,

$$
S_{i+1}=S_{i}-\mu\left(\frac{S_{i}}{1-S_{i}^{2}}\right) \Delta t_{i}+\varepsilon_{i+1} ; \quad \varepsilon_{i+1} \sim N\left(0, \sigma^{2}\left(t, S_{i}\right) \Delta t_{i}\right) .
$$

Applying this Maximum Likelihood method to our two-party preferred data, we found the MLE for $\sigma$ and $\mu$ are 0.28 and 3.98 respectively. Thus, our model becomes $d S=-3.98\left(\frac{S}{1-S^{2}}\right) d t+0.28 d W$. A simulation of the process is given in Figure 1(b). The time range is the same as Figure 1(a) and the qualitative similarities can be seen between the data and the simulated process.

\subsubsection{Winning probabilities, sampling and response errors}

In this section we calculate the probability that a party wins government conditional upon a known value of $S$ and describe the sampling and response errors. Historical observations show that exaggerated majorities are not uncommon in Australian federal and state politics and in other realms also. We assume that the probability of winning an election does not depend on the time since the last election. It is obvious that the probability of winning an election will be larger from a higher state rather than from a lower state.

The Australian House of Representative is composed of around 150 seats, and the party which wins the majority of seats holds government. We neglect the small number of seats that are won by the minor parties. Our approach assumes that the number of seats won depends on the true state $S$. The relationship is derived empirically, and this technique captures asymmetry in the electoral system, which may be overlooked in a parametric model. We define a quantity to measure the decisiveness of the election; the proportion of seats won, $N_{w} \in[0,1]$. Winning the election follows surely if $N_{w}>0.5$. Without the representative system and exaggerated majorities, it would follow that $N_{w}=\frac{1}{2} S+\frac{1}{2}$. Data from Australian Electoral Commission [http://www.aec.gov.au] for 22 federal elections since 1949 is used to 

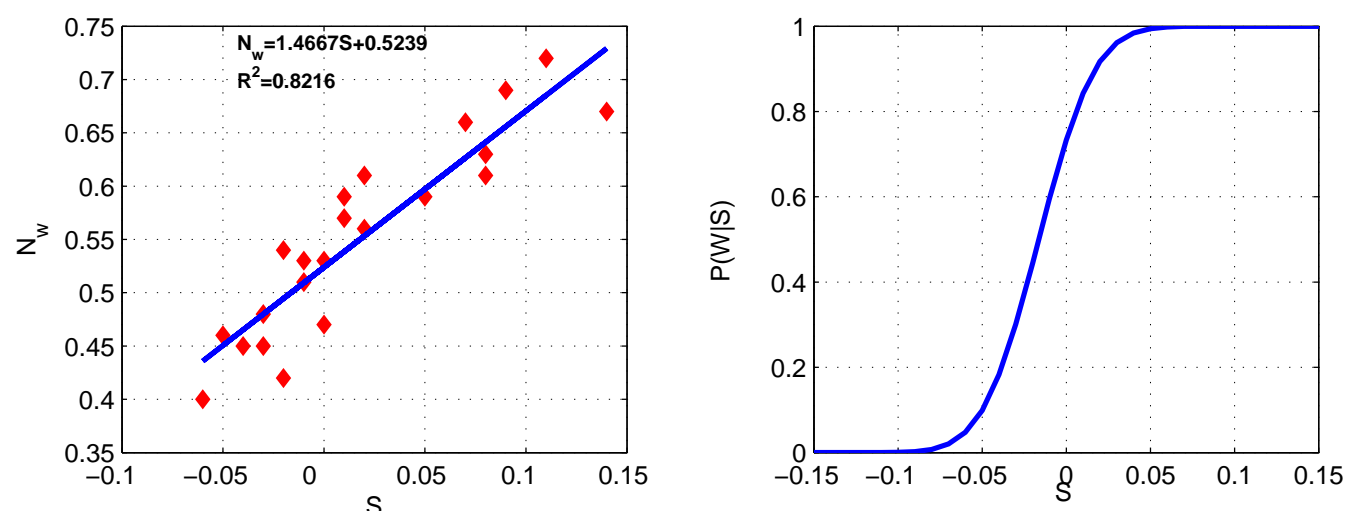

Figure 2: (a) Proportion of seats won for each $S$; (b) Probability of winning election from true state $S$

derive Figure 2(a). A regression is performed between observed true state $S$ and the resultant proportion of seats won $N_{w}$. Assuming normality and homoscedacity of residual errors, the model yields $N_{w}=0.524+1.47 \mathrm{~S}+\epsilon$ where $\epsilon \sim N(0,0.00148)$. It follows that $\operatorname{Pr}(W \mid S)=\operatorname{Pr}(X>0.5)$, where $X \sim N(0.524+1.47 S, 0.00148)$. We calculated this quantity and depict it in Figure 2(b).

There is much literature on the topic of response error, but not much quantification for the problem in our setting. The theory of sampling error is well understood and Kmietowicz [9] performs some analysis on the confidence interval for samples of $S$, and derives the sample error: $S E^{2}=\frac{1}{n}\left[1-S^{2}\right]$. In our setting, with $S \approx 0$, we have the bound $S E \leq 0.005$ (for $n=404$ ). The construction in finding an estimate for the sampling error $Q_{k j}$ is as follows. When $S \approx 0$, and $n$ is quite large, the true state $S$ will be normally distributed about the poll state with variance $\frac{1}{n}$. On the other hand, when $S$ is far away from zero, the true state will be normally distributed about poll state with variance $\frac{1}{n}\left(1-S^{2}\right)$. 

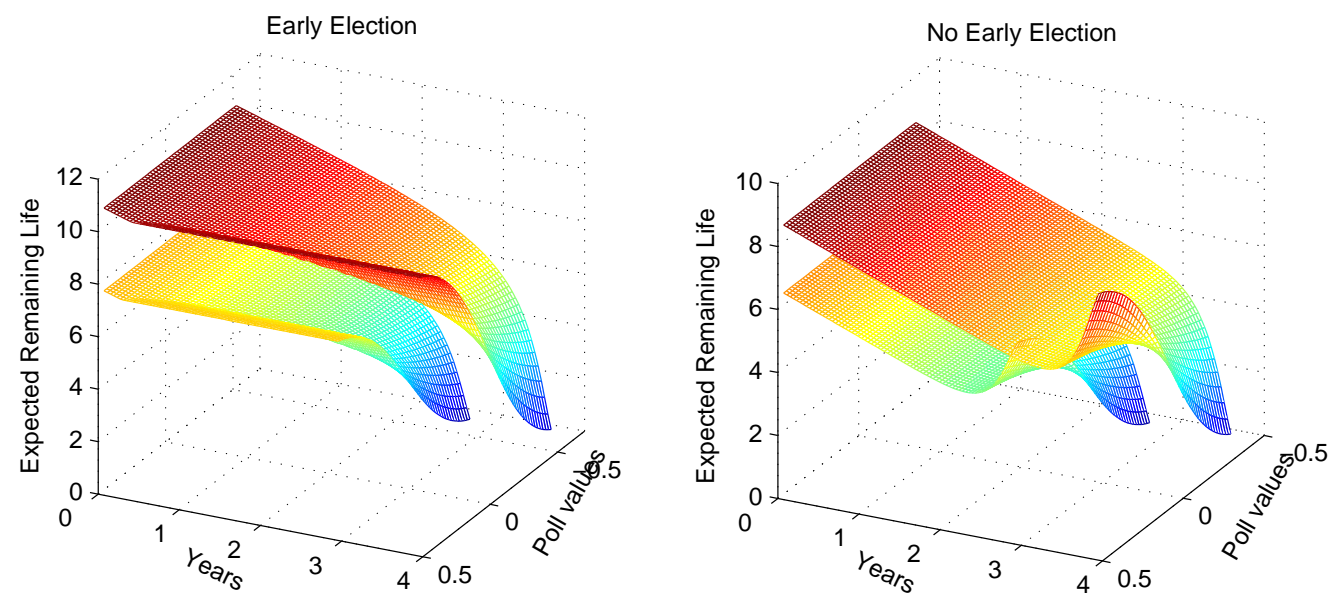

FiguRE 3: Expected remaining life -3 and 4 year terms: (a) early election permitted; (b) no early election.

\section{Results}

\subsection{Expected remaining life and exercise boundary}

We produce the expected remaining life in government to compare a threeyear term to a four-year term. Parameters were derived for the Australian House of Representatives data as discussed above. It has been debated whether three or four year terms are preferable. There was a referendum in 1988 to alter the Constitution to provide for 4 year maximum terms for members of both Houses of the Commonwealth Parliament, but only $32.92 \%$ of voters were in favour of 4 year terms, see [1]. We calculated the expected remaining life in government for each of these scenarios (see Figure 3). From that figure see that the expected remaining life is considerably longer for four year term because the government has more freedom to exercise the 



FiguRE 4: Exercise boundary for calling an election -3 and 4 year term.

early election option. Also, the expected remaining life at $t=0$ is almost constant and independent of states $S_{i}$. Further, observe the effect of parameters $\mu$ and $\sigma$ on the expected remaining life and we find that when $\mu$ or $\sigma$ become larger, the expected remaining life at $t=0$ becomes shorter. We also provide the result for the exercise boundary of a three year and four year term in Figure 4. From these figures, the exercise boundary is monotone in $\mu$ and $\sigma$. Larger value of $\mu$ corresponds with strong mean reversion in our model and larger $\sigma$ means larger volatility.

\subsection{No early election permitted}

While the Australian constitution permits the federal government to call early elections, the constitutions of other countries and even some of the Australian states are mandated only to hold elections with fixed terms. We compare the expected remaining life in government if the option for early exercise is removed. From equations (1) and (2), it is immediately apparent 
that the extra opportunities afforded by holding an option for early exercise. Results for the expected remaining life for three and four year term is given in Figure 3. Note that the expected remaining life is shorter than when we include the early election option.

\section{Conclusions and further research}

We have used a dynamic programming method to solve an early political election problem in the Australian Federal Election, using the two-party preferred data. We find the optimal control for government by locating the exercise boundary and the expected life in government given the current status in polls. Parameter estimation for the transition probabilities is obtained by the maximum likelihood method. We have fitted a mean reverting model and we found a strong rate of mean reversion. This supports the adage that "a week can be a long time in politics" as the collective memory of parties' successes and failures fades quite quickly. We also compare the expected remaining life for the maximum term of three and four year and found that in the four year term, the incumbent party will be in power for considerably longer. Also, at $t=0$ the expected remaining life is almost constant for both three and four year term (around 7.69 and 10.84 years, respectively), independent of states $S_{i}$ and presumably this is due to the strength of mean reversion. This condition also happened when we remove the early election option, giving the expected remaining life at $t=0$ of 6.48 and 8.64 years for three and four year term.

Modelling the opinion polls as a jump diffusion process instead as a mean reverting process as we have done here, with introduction of random jumps as major events, is also an extension that can be considered. Also the party may have control over the polls with timely announcements. Optimizing the lead time $T_{L}$, constrained between 33 and 68 days is also another avenue for pursuit. 


\section{References}

[1] Australian Electoral Commission 1988 Referendums: Statistics. Canberra: Author, 1990. C29

[2] Balke, N.S. The Rational Timing of Parliamentary Elections. Public Choice, 65, 201-216, 1990. C18, C20

[3] Black, F. \& Scholes, M. The Pricing of Options and Corporate Liabilities. The Journal of Political Economy, 81(3), 637-654, 1973. C26

[4] Chowdhury, A.R. Political Surfing over Economic Waves:

Parliamentary Election Timing in India. American Journal of Political Sciences, 37(4), 1100-1118, 1993. C18

[5] Ito, T. Endogeneous Election Timings and Political Business Cycles in Japan. NBER Working Paper No. 3128, 1989. C18

[6] Karlin, S. \& Taylor, H.M. A Second Course In Stochastic Processes. New York: Academic Press, 1981. C26

[7] Kayser, M.A. Who Surfs, Who Manipulates? The Determinants of Opportunistic Election Timing and Electorally Motivated Economic Intervention. Nuffield College Politics Working Paper, 2003. C18, C20

[8] Kinsey, L.C.Topology of Surfaces. New York: Springer-Verlag, 1993. C25

[9] Kmietowicz, Z.M. Sampling Errors in Political Polls. Teaching Statistics, 16(3), 70-74, 1994. C28

[10] Kushner, H.J. \& Dupuis, P.G.Numerical Methods for Stochastic Control Problems In Continuous Time. New York: Springer-Verlag, 1992. C23 
[11] Newspoll. The Australian, p.6, October 22, 2002. C20

[12] Smith, A. Election Timing in Majoritarian Parliaments. Paper presented at the Annual Meeting of the American Political Science Association, Washington, DC, 2000. C18, C20

[13] Smith, A. Election Timing. Book manuscript. Retrieved July, 2003 http://www.yale.edu/plsc506a/electiontiming.pdf C18

[14] Wilson, P. (Ed.) The Australian Political Almanac (1st ed.). South Yarra, Vic: Hardie Grant Books, 2002. C20 